\title{
Trace lipid from whey-mineral complex enhances calcium availability in young ovariectomized rats
}

\author{
BY H. TSUCHITA AND T. KUWATA \\ Nutritional Science Institute, Meiji Milk Products Co. Ltd., 1-21-3 Sakaecho, Higashimurayama, \\ Tokyo 189, Japan
}

(Received 1 March 1994 - Revised 7 June 1994 - Accepted 24 June 1994)

\begin{abstract}
The effects of the trace lipids (L1 and L2) extracted from two kinds of whey-mineral complex on bone metabolism were studied in young ovariectomized (OVX) rats. The concentrations of oestradiol in the $\mathrm{L1}$ and $\mathrm{L2}$ oils were 305 and $1313 \mathrm{pg} / \mathrm{ml}$ respectively, while the concentrations of progesterone were 34.3 and $36.9 \mathrm{ng} / \mathrm{ml}$ respectively. Trace amounts of $1 \alpha, 25$-dihydroxycholecalciferol $\left(1 \alpha, 25-(\mathrm{OH})_{2} \mathrm{D}\right)$ were detected: $56 \mathrm{pg} / \mathrm{ml}$ in the $\mathrm{L1}$ oil and $132 \mathrm{pg} / \mathrm{ml}$ in the $\mathrm{L} 2$ oil. The OVX rats were orally given $0.4 \mathrm{ml}$ each test oil twice weekly. Other animals were given with only a vehicle (control) or an oil mixture with similar levels of oestradiol and progesterone to those in $\mathrm{L} 2$ oil (PE oil) for comparison. The Ca absorption rate, bone density of the humerus and femoral $\mathrm{Ca}$ content in the rats given $\mathrm{L} 2$ were significantly higher than those in the control rats $(P<0.05)$. Serum calcitonin and $1 \alpha, 25-(\mathrm{OH})_{2} \mathrm{D}$ from rats given $\mathrm{L2}$ were both significantly higher than those from the control rats, while serum progesterone in the L2 group was slightly lower. It is suggested that the bone metabolism of rats given L2 reflected the compound effect of $1,25-(\mathrm{OH})_{2} \mathrm{D}$ and oestradiol in the $\mathrm{L} 2$ oil. In contrast, the relatively low level of these hormones might have been associated with the mediocre bone characteristics of the L1 group. It is suggested from these results that the trace level of hormones could be one of the reasons why whey-mineral complex showed good Ca availability.
\end{abstract}

Bone: Calcium: Hormones: Rat: Whey-mineral complex

Whey-mineral complex (WMC) prepared from acidic milk whey has been reported as a mineral supplement due to its good mineral availability (Igarashi et al. 1990; Tsuchita et al. 1992). We have previously implicated the influence of components other than the minerals in WMC on bone metabolism by comparing two WMC with different compositions (Tsuchita et al. 1993). Preliminary analyses indicated that the lipid extracted from WMC contained trace amounts of progesterone and oestradiol. Although sex steroid and corticosteroid hormones are related to bone metabolism (Nordin et al. 1981 ; Roe et al. 1988), the hormones naturally present in milk have practically no effect when taken orally. For example, the level of oestrogen in milk and milk products is too low for biological activity (Hoffmann, 1977). However, the composition of the lipid extracted from WMC was different from that of milk fat, showing less triacylglycerol, but larger amounts of cholesterol or compound lipids, so that the overall effect of the lipid on bone metabolism was not clear. The present study was conducted to determine whether the trace lipid from WMC would influence bone metabolism in young ovariectomized rats and to evaluate the contribution of a very low dose of oestradiol and progesterone. 
Table 1. Chemical and hormone composition of two whey-mineral complexes (WMC)

\begin{tabular}{|c|c|c|}
\hline & WMC1 & WMC2 \\
\hline $\begin{array}{l}\text { Major components (g/kg) } \\
\text { Moisture* } \\
\text { Protein } \dagger \\
\text { Fat } \ddagger \\
\text { Lactose§ } \\
\text { Calcium } \| \\
\text { Phosphorus } \| \\
\text { Magnesium } \|\end{array}$ & $\begin{array}{c}59 \\
23 \cdot 0 \\
2 \\
260 \cdot 0 \\
182 \\
84 \\
3 \cdot 3\end{array}$ & $\begin{array}{c}90 \\
104 \cdot 6 \\
2 \\
3 \cdot 3 \\
264 \\
146 \\
4.5\end{array}$ \\
\hline $\begin{array}{l}\text { Hormones** } \\
\text { Oestradiol }(\mathrm{pg} / \mathrm{g}) \\
\text { Progesterone }(\mathrm{ng} / \mathrm{g}) \\
\text { la,25-dihydroxycholecalciferol }(\mathrm{pg} / \mathrm{g})\end{array}$ & $\begin{array}{l}5 \cdot 3 \\
0 \cdot 88 \\
1 \cdot 0\end{array}$ & $\begin{array}{c}33 \cdot 6 \\
0.94 \\
3 \cdot 4\end{array}$ \\
\hline
\end{tabular}

* Weight loss after heating at $98^{\circ}$ for $5 \mathrm{~h}$.

$\dagger$ Kjeldahl $\mathbf{N} \times 6.38$.

$\ddagger$ Röse-Gottlieb method.

$\S$ Enzymic method using a measuring kit (Boehringer Mannheim Yamanouchi Co., Japan).

$\|$ Atomic absorption spectrophotometry.

II Spectrophotometric method (Allen, 1940).

** Hormones were determined in the lipid extracted from the WMC by the method described below. Assays were carried out using diagnostic measuring kits: oestradiol, progesterone, Diagnostic Products Co., CA, USA; 1 $\alpha, 25$-dihydroxycholecalciferol, Amersham Japan Co., Tokyo, Japan.

\section{MATERIALS AND METHODS}

\section{Preparation of lipids}

Two types of WMC (WMC1 and WMC2) prepared by separate methods were used as lipid sources in the extractions (Tsuchita et al. 1993). Their chemical compositions and hormone contents are shown in Table 1. Lipid was extracted from the material with diethyl ether for $6 \mathrm{~h}$ using Soxhlet apparatus. The treated material was dried and then mixed with a fivefold volume of a chloroform-methanol $(2: 1, \mathrm{v} / \mathrm{v})$ mixture in a Waring blender. The chloroform-methanol extraction was conducted three times. After dehydrating by adding anhydrous $\mathrm{Na}_{2} \mathrm{SO}_{4}$, the solvents were removed from the diethyl ether extract and the chloroform-methanol extract by vacuum rotary evaporation. The diethyl ether extract and chloroform-methanol extract were combined and mixed ( $\mathrm{L} 1$ from $\mathrm{WMCl}$ and $\mathrm{L} 2$ from WMC2). Using thin-layer chromatography, the lipid extracted from these WMC was shown to contain larger amounts of cholesterol, its esters and phospholipid, and less triacyglycerol compared with the lipid composition of butter oil (results not shown). To administer the lipids to eight rats, $\mathrm{L} 1$ and $\mathrm{L} 2$ were newly obtained from $1520 \mathrm{~g} \mathrm{WMC1}$ and $1040 \mathrm{~g}$ WMC2. Assuming that eight rats each consume $20 \mathrm{~g}$ diet daily for $28 \mathrm{~d}, 1520 \mathrm{~g}$ WMC1 and $1040 \mathrm{~g} \mathrm{WMC2}$ represent ten times the amounts consumed as a $6 \mathrm{~g} / \mathrm{kg} \mathrm{Ca}$ diet when WMC1 or WMC2 is added as the sole source of $\mathrm{Ca}$. The recovery of $\mathrm{L} 1$ was $1.86 \mathrm{~g}$, and of $\mathrm{L} 2,1.29 \mathrm{~g}$. L1 or L2 was dissolved in $0.2 \mathrm{ml}$ ethanol and then mixed with $25.0 \mathrm{ml}$ soyabean oil as a vehicle (L1 oil or L2 oil). The concentrations of oestradiol in the L1 and $\mathrm{L} 2$ oils were 305 and $1313 \mathrm{pg} / \mathrm{ml}$ respectively, while the concentrations of progesterone were 34.3 and $36.9 \mathrm{ng} / \mathrm{ml}$ respectively. A trace amount of $1 \alpha, 25$-dihydroxycholecalciferol $\left(1 \alpha, 25-(\mathrm{OH})_{2} \mathrm{D}\right)$ was detected: $56 \mathrm{pg} / \mathrm{ml}$ in the $\mathrm{L} 1$ oil and $132 \mathrm{pg} / \mathrm{ml}$ in the $\mathrm{L} 2$ oil. An oil mixture including standard progesterone and $17 \beta$-oestradiol (Sigma Chemical Co., MO, USA) was prepared for comparison (PE oil: progesterone, $40.0 \mathrm{ng} / \mathrm{ml} ; 17 \beta$-oestradiol, $1427 \mathrm{pg} / \mathrm{ml})$. 
Animals and diets

Forty 3-week-old Sprague-Dawley female rats (Japan SLC, Shizuoka, Japan) were housed in individual aluminium cages in a temperature-controlled $\left(23 \pm 2^{\circ}\right)$ room with $50 \pm 5 \%$ humidity and a $12 \mathrm{~h}$ light-dark cycle, and fed on a stock diet (CE-7, Clea Japan, Tokyo, Japan). On the fifth day of feeding, thirty-two rats were ovariectomized (OVX) under diethyl ester anaesthesia. The remaining animals were sham-operated (SHAM). At 1 week after the operation the rats were fed on a low-Ca diet ( $\mathrm{Ca}, 0 \cdot 1 \mathrm{~g} / \mathrm{kg} \operatorname{diet} ; \mathbf{P}, 3 \mathrm{~g} / \mathrm{kg}$ diet). After $30 \mathrm{~d}$ feeding the OVX rats were separated into four groups of eight animals each according to a similar mean body weight of $208 \mathrm{~g}$. Four groups of OVX rats and one group of SHAM rats were then fed ad lib. on a Ca-supplemented diet $(\mathrm{Ca}, 3 \mathrm{~g} / \mathrm{kg} \operatorname{diet} ; \mathrm{P}, 3 \mathrm{~g} / \mathrm{kg}$ diet) and deionized water for $28 \mathrm{~d}$. The low-Ca diet and the $\mathrm{Ca}$-supplemented diet were prepared according to the AIN-76A purified diet composition with slight modification for minerals (American Institute of Nutrition, 1977, 1980). During the feeding period, three groups of OVX rats were orally given $0.4 \mathrm{ml}$ of one of the test oils ( $\mathrm{L} 1$ oil, L2 oil, or PE oil) twice weekly. One group of OVX rats and the SHAM rats were given only the vehicle. Urine samples were collected during days 2-4, 9-11, 16-18, and 23-25 of the experimental period to determine hydroxyproline and cyclic AMP concentrations. Faecal samples were also collected during days $23-25$ for a mineral balance study. Body weight and feed intake were recorded three times weekly. After $28 \mathrm{~d}$ the animals were fasted overnight, anaesthetized with an intraperitoneal injection of sodium pentobarbital $(40 \mathrm{mg} / \mathrm{kg}$ body weight), and blood samples were taken from the aorta ventralis to determine biochemical indices. Both femurs, humeri, and ulnae were excised, and the surrounding flesh was removed.

\section{Analytical methods}

The bone densities for the humerus and ulna were obtained by microphotodensitometry of roentgenographic images as previously reported (Tsuchita et al. 1993). The femurs and the faecal samples were dried, weighed, and ashed overnight in a muffle furnace at $600^{\circ}$. The ashed samples were then dissolved in $1 \mathrm{M}-\mathrm{HNO}_{3}$ for $\mathrm{Ca}$ analysis by atomic absorption spectrophotometry (Shimadzu AA-640-13, Shimadzu Corporation, Kyoto, Japan). P was determined by a spectrophotometric method (Allen, 1940), and urinary Ca content was determined directly as already described. Plasma $\mathrm{Ca}$, inorganic $\mathbf{P}(\mathrm{Pi})$ and alkaline phosphatase (EC 3.1.3.1) activity were determined using an autoanalyzer (Hitachi 736, Hitachi Ltd., Tokyo, Japan), and urinary hydroxyproline was estimated colorimetrically (Bergman \& Loxley, 1970). Cyclic AMP was measured by a competitive binding assay, using a cyclic AMP $\left[{ }^{3} \mathrm{H}\right]$ assay system (Amersham Japan Co., Tokyo, Japan). Serum and urinary creatinine was determined colorimetrically using a measuring kit (Wako Pure Chemical Ind., Osaka, Japan). Oestradiol and progesterone in the serum and extracted lipids were measured by a radioimmunoassay, using diagnostic assay kits (Diagnostic Products Corporation, CA, USA). Serum immunoreactive rat calcitonin was evaluated by a diagnostic measuring kit (Mitsubishi Petrochemical Co., Tokyo, Japan), based on human calcitonin, which recognizes human calcitonin 1-32 and has previously been shown to detect rat calcitonin (Roos et al. 1978). 1 $\alpha, 25-(\mathrm{OH})_{2} \mathrm{D}$ was measured by a competitive radio-binding assay, following a non-HPLC sample purification procedure, using a commercial assay system (Amersham Japan Co.).

\section{Statistical analysis}

All data were analysed by a one-way analysis of variance (ANOVA). When significant $F$ ratios were found, individual means were compared by the Bonferroni test $(P<0.05)$. 


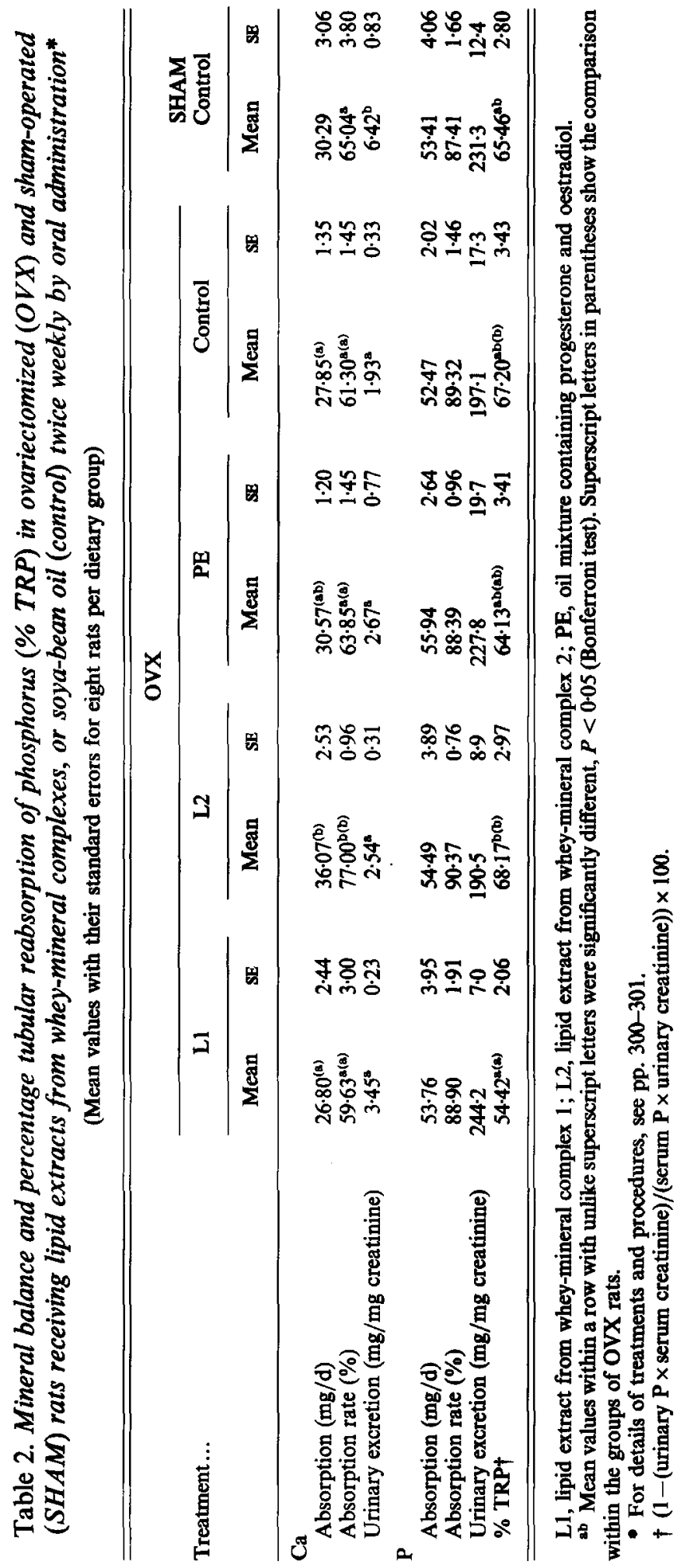




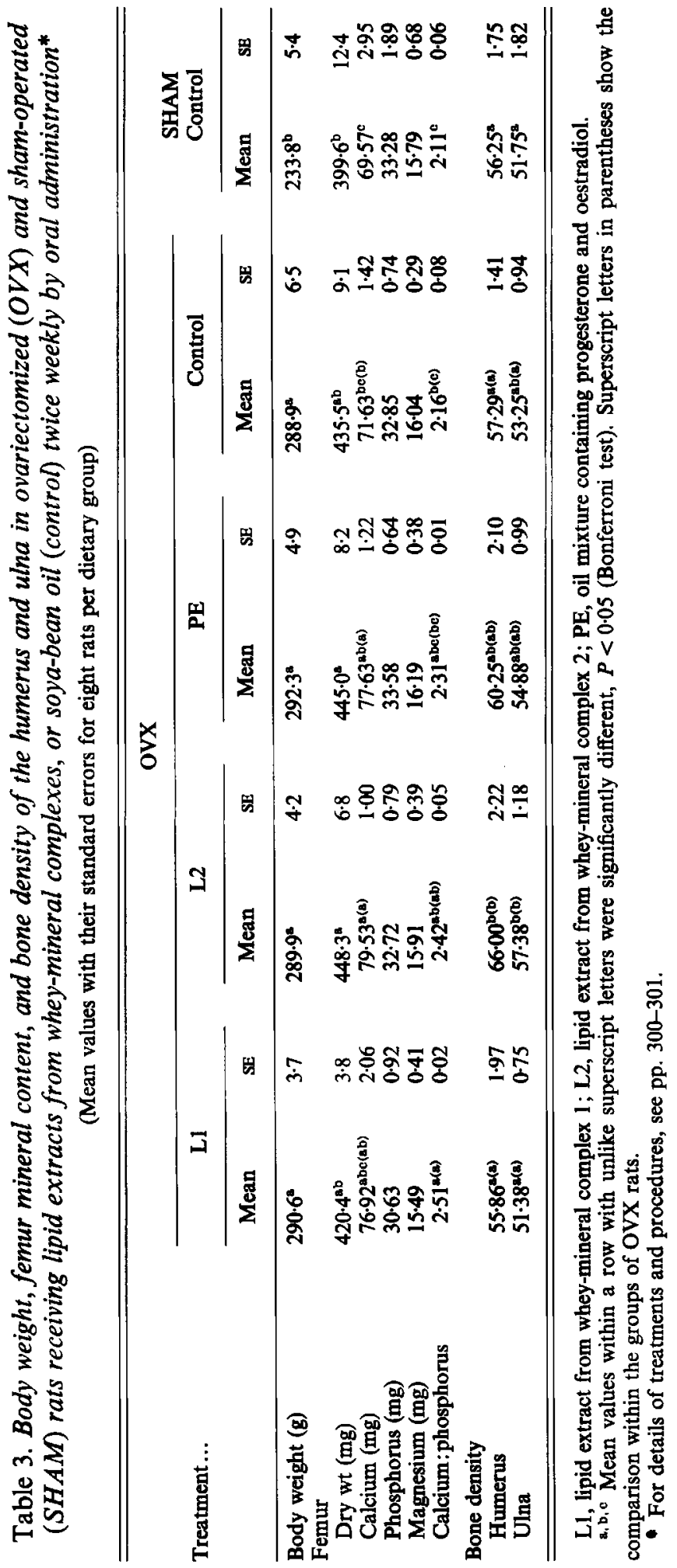


H. TSUCHITA AND T. KUWATA

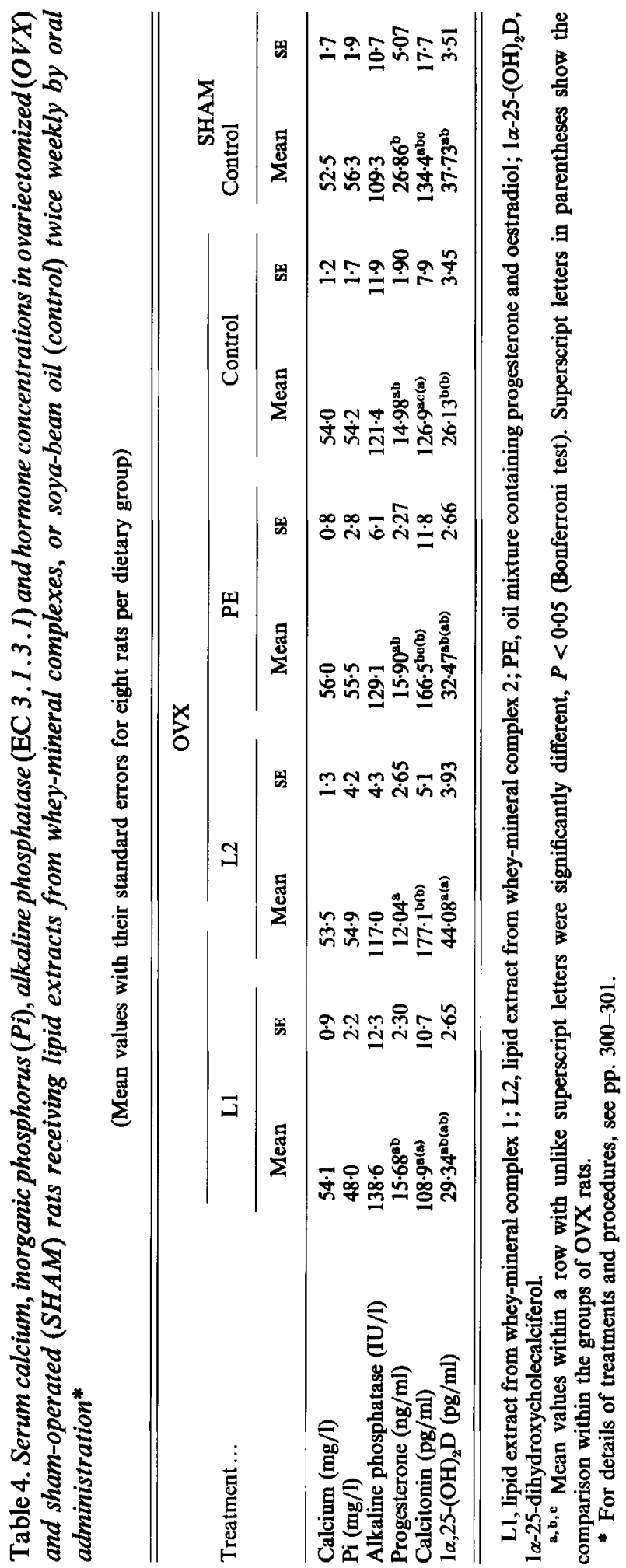



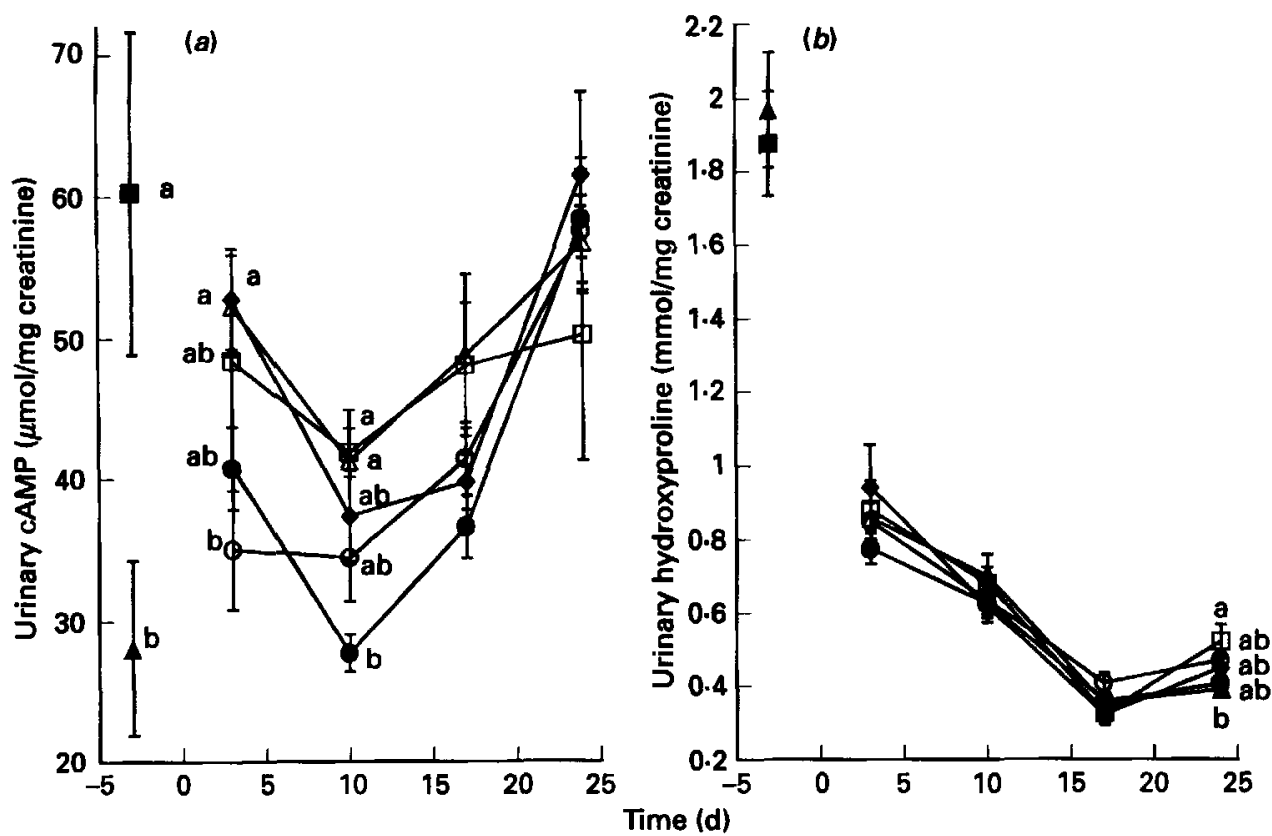

Fig. 1. (a) Urinary cyclic AMP excretion and (b) urinary hydroxyproline excretion by ovariectomized (OVX) rats receiving lipid extracts from whey-mineral complexes ( $L 1, O$ and $L 2, O$ ), an oil mixture containing progesterone and oestradiol (PE oil, $\diamond$ ) or soya-bean oil (control, $\triangle$ ) twice weekly by oral administration. Sham-operated (SHAM) rats also received soya-bean oil $(\square)$. Values for the OVX rats $(\Delta)$ and SHAM rats $(\square)$ were obtained at the end of a period on a low-Ca diet. All animals were fed on a Ca-supplemented diet from days 0 to 28 . Values are means with their standard errors represented by vertical bars. Mean values for the same day not sharing a common superscript letter were significantly different, $P<0.05$ (Bonferroni test).

\section{RESULTS}

\section{Mineral balance}

The Ca absorption rate in rats given the $\mathrm{L} 2$ oil was significantly higher than in all the other groups (Table 2). The $\mathrm{Ca}$ absorption in rats given $\mathrm{L} 2$ oil was also high among the groups of OVX rats. The $\mathrm{Ca}$ absorption and the absorption rate of the $\mathrm{L} 1$ group were similar to those of the control (OVX) group. The highest urinary Ca excretion was observed in the SHAM group, while there was no significant difference in the values among the groups of OVX rats. There was no significant difference in quantitative values for $P$ balance among the groups (Table 2). The percentage tubular reabsorption of P (\% TRP) for the L1 group was significantly lower than that for the $\mathrm{L} 2$ and control groups.

\section{Bone mineral analysis and bone density}

The final body weight of the SHAM group was significantly lower than that of the groups of OVX rats, as previously reported (Clark \& Tarttelin, 1982), but no significant difference was observed among the groups of OVX rats (Table 3). There was also no significant difference in the dry weight of the femur among the groups of OVX rats (Table 3). The Ca content in the femur of the L2 group was significantly higher than that of the control and SHAM groups, the value for the PE group also being high when compared with the other groups of OVX rats. All the groups had similar $\mathrm{P}$ and $\mathrm{Mg}$ contents in the femur, although the L1 group had a higher femoral Ca:P ratio than did the control and SHAM groups (Table 3). The rats given the L2 oil showed significantly higher bone density for the 
humerus than all other groups except the PE group (Table 3). Likewise, the bone density of the ulna in the L2 group was higher than that of the control and L1 groups.

\section{Biochemical indices in serum and urine}

There were no significant differences in serum $\mathrm{Ca}, \mathrm{Pi}$ and alkaline phosphatase activity among the five groups (Table 4). Serum progesterone in the rats given the L2 oil was significantly lower than that in the SHAM rats given the vehicle, although the difference was not significant when compared with the other groups of OVX rats. Serum oestradiol was only detected in a few samples $(>10 \mathrm{pg} / \mathrm{ml}$ ), and these values are not shown. Serum calcitonin in the L2 group was significantly higher than that in the L1 and control groups (Table 4). The value for the PE group was also higher than that for the Ll group when compared with the groups of OVX rats. Serum $1 \alpha, 25-(\mathrm{OH})_{2} \mathrm{D}$ in the rats given the $\mathrm{L} 2$ oil was significantly higher than that in the rats given the control oil, although no significant difference was observed among the other groups (Table 4). The animals given the L1 and L2 oils tended to give a lower urinary cyclic AMP excretion; the value for the L1 group was significantly lower during days $2-4$, and that for the L2 group was lower than that for the control group during days 9-11 (Fig. 1). The change in urinary hydroxyproline excretion was similar among the groups of OVX rats throughout the experimental period, although the values were much higher at the end of the period of low-Ca-diet feeding (Fig. 1).

\section{DISCUSSION \\ Calcium and phosphorus balance}

The present study shows the marked effect of the lipid extracted from WMC, especially of $\mathrm{L} 2$, on Ca absorption and bone mineral deposition. In contrast with this, no effect on Ca absorption was reportedly produced by supplementing with WMC2 in young male rats, although the bone density was high (Tsuchita et al. 1993). This discrepancy might have arisen from the different dose of the lipid; the total amount of L2 administered to a rat was more than ten times as much as the lipid from WMC2 in the diet. The effect of oestrogen administration on intestinal $\mathrm{Ca}$ absorption has been reported (Russell et al. 1986), and an increase in the serum level of $1 \alpha, 25-(\mathrm{OH})_{2} \mathrm{D}$ has been shown in normal rats (Baksi \& Kenny, 1978) and OVX rats (Ash \& Goldin, 1988). The serum $1 \alpha, 25-(\mathrm{OH})_{2} \mathrm{D}$ level in the rats given L2 was higher than that in the rats given standard $17 \beta$-oestradiol and progesterone, whose concentrations were similar to those in $\mathrm{L} 2$. Therefore, $1 \alpha, 25-(\mathrm{OH})_{2} \mathrm{D}$ rather than oestradiol contained in $\mathrm{L} 2$ would have contributed to the high level of serum $1 \alpha, 25-(\mathrm{OH})_{2} \mathrm{D}$ that caused the high $\mathrm{Ca}$ absorption in those rats given $\mathrm{L} 2$ (Armbrecht et al. 1980). It is well known that parathyroid hormone (PTH) is one of the most important factors for stimulating $1 \alpha$-hydroxylase ( $E C 1.14 .13 .13)$ activity, although the relatively low urinary cyclic AMP excretion from the rats given L1 and L2 does not support an increase in PTH.

The level of oestradiol given to the L2 group was $405 \mathrm{pg} / \mathrm{rat}$ per d or $3240 \mathrm{pg} / \mathrm{rat}$ in total during the experimental period, which is lower than the levels reported in the literature: $5.0 \mu \mathrm{g} / 100 \mathrm{~g}$ body weight (Russell et al. 1986); $1.0,2.5$, and $5.0 \mu \mathrm{g} / 100 \mathrm{~g}$ body weight (Wronski et al. 1988 b). Oestrogen administration caused an increase in serum calcitonin in humans (Austin \& Heath, 1981), and in rats (First et al. 1981). While the administration of oestradiol to the L2 and PE groups could have been associated with a higher level of serum calcitonin, the rats given $\mathrm{L} 1$ gave the lowest value among all the groups. This could partly have been due to the relatively low level of oestradiol in L1. However, whether an effect of progesterone on oestradiol or of another unknown factor in L1 was involved remains unclear. 
The $P$ retention in rats fed with WMC tended to be higher than in rats fed with $\mathrm{CaCO}_{3}$ (Tsuchita et al. 1993), but no significant difference in $P$ balance was observed among the experimental groups. However, the $\mathrm{P}$ metabolism of those rats given $\mathrm{L} 1$ seems to have been affected; the \% TRP and serum Pi in the L1 group were slightly lower than the levels in the other groups, although the differences were not significant.

\section{Bone mineralization}

Histological studies have shown that the initial rapid phase of bone loss in OVX rats is associated with an increased bone turnover (Wronski et al. 1986, 1988a). Oestrogen treatment prevents osteopenia and depresses the bone turnover in OVX rats (Wronski et $a l .1988 b$ ) via the function of PTH or calcitonin (Gennari et al. 1987). In the present study, not only ovariectomy but also a low-Ca diet accelerated the bone loss in OVX rats (Kalu et al. 1989) as shown by the urinary hydroxyproline excretion (Fig. 1). However, any inhibitory effect of oestradiol in the test oils on bone turnover is obscure, no significant difference in urinary hydroxyproline being apparent among the OVX rats after feeding with a Ca-supplemented diet. On the other hand, the high serum calcitonin and low urinary cyclic AMP excretion in rats given $\mathrm{L} 2$ suggest the effect of oestrogen on bone metabolism. It has been shown that exogenous $1,25-(\mathrm{OH})_{2} \mathrm{D}$ increases bone mass in OVX rats as well as in intact rats (Lindgren \& DeLuca, 1982). Therefore, the high bone density of the humerus and high femoral Ca content in those rats given $\mathrm{L} 2$ could reflect the effect of oestradiol and $1 \alpha, 25-(\mathrm{OH})_{2} \mathrm{D}$ on the bone, in addition to the high $\mathrm{Ca}$ absorption. The $\mathrm{Ca}$ content and $\mathrm{Ca}: \mathrm{P}$ ratio of the femur in the $\mathrm{L} 1$ group were similar to the figures for the $\mathrm{L} 2$ and PE groups, while the bone density of the humerus was similar to that of the control group. The different bone characteristics between the L1 and L2 groups might have been caused by the levels of oestradiol and $1 \alpha, 25-(\mathrm{OH})_{2} \mathrm{D}$ in the test oils. The administration of progesterone prevents bone loss in OVX rats (Lindsay et al. 1978; Barbagallo et al. 1989; Barengolts et al. 1991), but the combination of oestrogen and progesterone has no effect on bone minerals (Lindsay et al. 1978; Barbagallo et al. 1989). Another report suggests that progesterone antagonizes the oestrogen-related inhibition of bone formation (Turner $e t$ al. 1989). Therefore, although the concentrations of progesterone in L1 and L2 were very small when compared with the dose used in these reported studies, the smaller oestradiol:progesterone ratio in L1 than in L2 might have affected bone formation.

\section{Hormones in milk and milk products}

An advance in measuring hormones using a radioimmunoassay technique enables comparison among the values reported for milk and milk products (Koldovsky \& Thornburg, 1987). Processing milk causes a large part of the steroid hormones to move with the fat; progesterone and oestrogens are contained in butter to a much higher level than in milk or whey (Hoffmann, 1977; Wolford \& Argoudelis, 1979). The level of naturally occurring hormones in dairy products reported in the literature is so small that no biological significance has been attributed to them (Hoffmann, 1977). In fact, there has been no study to show any effect of the hormones in milk on bone in animals or humans, probably because of their low level or of the obvious effect of $\mathrm{Ca}$ in milk. However, the present study shows the effect of oestradiol and progesterone in PE oil as well as in L2 oil on bone metabolism in OVX rats. The concentrations of oestradiol in the L1 and L2 oils (305 and $1313 \mathrm{pg} / \mathrm{ml}$ ) were higher than that in butter $(82.3 \mathrm{pg} / \mathrm{g}$; Wolford \& Argoudelis, 1979), whereas the concentrations of progesterone in the L1 and L2 oils (34.3 and $36.9 \mathrm{ng} / \mathrm{ml})$ were lower than that in butter $(132.9 \mathrm{ng} / \mathrm{g}$, Ginther et al. 1976). The concentrations of $1,25-(\mathrm{OH})_{2} \mathrm{D}$ in the $\mathrm{L} 1$ and $\mathrm{L} 2$ oils $(56$ and $132 \mathrm{pg} / \mathrm{ml})$ were comparable with that in milk $(29 \mathrm{pg} / \mathrm{ml}$; Takeuchi et al. 1988). Therefore, although the level of 
hormones was very low, it is suggested that the bone metabolism in rats given $\mathrm{L} 2$ reflects the compound effect of $1,25-(\mathrm{OH})_{2} \mathrm{D}$ and oestradiol in L2. Other steroid hormones such as oestrone, oestriol, androgens and corticosteroids have been detected in milk and milk products (Hoffmann, 1977; Pope \& Swinburne, 1980), and these have some effects on bone metabolism (Schot \& Schuurs, 1990). The results of a preliminary analysis by a radioimmunoassay showed trace amounts of androstanedione and dehydroepiandrosterone, but no oestrone in the lipid extracted from WMC (results not shown). Further work to analyse these hormones or unknown components in the lipid and to evaluate the effect on bone metabolism in OVX rats would contribute to understanding of the good $\mathrm{Ca}$ availability from WMC.

Postmenopausal bone loss has been prevented by treatment with oestrogen and by $\mathrm{Ca}$ supplementation (Ettinger et al. 1987; Riis et al. 1987). In this regard, WMC with trace amounts of $1,25-(\mathrm{OH})_{2} \mathrm{D}$ and oestradiol could be a good mineral supplement for those who are at risk of osteoporosis.

The authors are grateful to Dr T. Inomata, Azabu University, for the bone density analyses and I. Sekiguchi for the mineral analyses.

\section{REFERENCES}

Allen, R. J. L. (1940). The estimation of phosphorus. Biochemical Journal 34, 858-865.

American Institute of Nutrition (1977). Report of the American Institute of Nutrition ad hoc committee on standards for nutritional studies. Journal of Nutrition 107, 1340-1348.

American Institute of Nutrition (1980). Second report of the ad hoc committee on standards for nutritional studies. Journal of Nutrition 110, 1726.

Armbrecht, H. J., Zenser, T. V. \& Davis, B. B. (1980). Effect of vitamin D metabolites on intestinal calcium absorption and calcium-binding protein in young and adult rats. Endocrinology 106, 469-475.

Ash, S. L. \& Goldin, B. R. (1988). Effects of age and estrogen on renal vitamin D metabolism in the female rat. American Journal of Clinical Nutrition 47, 694-699.

Austin, L. A. \& Heath, H. (1991). Physiology and pathophysiology. New England Journal of Medicine 304, 269-278.

Baksi, S. \& Kenny, A. D. (1978). Does estradiol stimulate in vivo production of 1,25 -dihydroxyvitamin $D_{s}$ in the rat? Life Sciences 22, 787-792.

Barbagallo, M., Carbognani, A., Palummeri, E., Chiavarini, M., Pedrazzoni, M., Bracchi, P. G. \& Passeri, M. (1989). The comparative effect of ovarian hormone administration on bone mineral status in oophorectomized rats. Bone 10, 113-116.

Barengolts, E. I., Curry, D. J., Botsis, J. \& Kukreja, S. C. (1991). Comparison of the effects of progesterone and estrogen on established bone loss in ovariectomized aged rats. In The Aged Rat Model for Bone Biology Studies, pp. 105-111 [W. S. S. Jee, editor]. Chicago: Scanning Microscopy International.

Bergman, I. \& Loxley, R. (1970). The determination of hydroxyproline in urine hydrolysates. Clinica Chimica Acta 27, 347-349.

Clark, R. G. \& Tarttelin, M. F. (1982). Some effects of ovariectomy and estrogen replacement on body composition in the rat. Physiology and Behavior 28, 963-969.

Ettinger, B., Genant, H. K. \& Cann, C. E. (1987). Postmenopausal bone loss is prevented by treatment with lowdosage estrogen with calcium. Annals of Internal Medicine 106, 40-45.

First, B. P., Miller, M. \& Deftos, L. J. (1981). Effects of oophorectomy (OOPHX) and estrogen replacement on calcitonin levels in sexually mature female rats. Calcified Tissue International 33, s304.

Gennari, C., Agnusdei, D., Civitelli, R., Nardi, P. \& Montagnani, M. (1987). Effects of estrogens on vitamin D metabolism in postmenopausal osteoporotic women. In Postmenopausal Hormonal Therapy: Benefits and Risks, pp. 243-253 [P. Fioretti, C. Flamigni, V. M. Jasonnii and G. B. Melis, editors]. New York: Raven Press.

Ginther, O. J., Nuti, L. C., Garcia, M. C., Wentworth, B. C. \& Tyler, W. J. (1976). Factors affecting progesterone concentration in cow's milk and dairy products. Journal of Animal Science 42, 155-159.

Hoffmann, B. (1977). Occurrence and relevance of hormones in milk. Milchwissenschaft 32, 477-482.

Igarashi, C., Ezawa, I. \& Ogata, E. (1990). Effects of whey calcium on bone metabolism in ovariectomized osteoporosis modes rats. Nippon Eiyo Shokuryo Gakkaishi 43, 437-443.

Kalu, D. K., Liu, C.-C., Hardin, R. \& Hollis, B. W. (1989). The aged rat model of ovarian hormone deficiency bone loss. Endocrinology 124, 7-16.

Koldovsky, O. \& Thornburg, W. (1987). Review. Hormones in milk. Journal of Pediatric Gastroenterology and Nutrition 6, 172-196. 
Lindgren, U. \& DeLuca, H. F. (1982). Role of parathyroid hormone and 1,25-dihydroxyvitamin $D_{3}$ in the development of osteopenia in oophorectomized rats. Calcified Tissue International 34, 510-514.

Lindsay, R., Aitken, J. M., Hart, D. M. \& Purdie, D. (1978). The effect of ovarian sex steroids on bone mineral status in the oöphorectomized rat and in the human. Postgraduate Medical Journal 54, Suppl. 2, 50-58.

Nordin, B. E. C., Marshall, D. H., Francis, R. M. \& Crilly, R. G. (1981). The effects of sex steroid and corticosteroid hormones on bone. Journal of Steroid Biochemistry 15, 171-174.

Pope, G. S. \& Swinburne, J. K. (1980). Reviews of the progress of dairy science. Hormones in milk: their physiological significance and value as diagnostic aids. Journal of Dairy Research 47, 427-449.

Riis, B., Thomsen, K. \& Christiansen, C. (1987). Does calcium supplementation prevent postmenopausal bone loss? A double-blind, controlled clinical study. New England Journal of Medicine 316, 173-177.

Roe, V. G. T. F., Gebbens, D. T., Schulz, E. E., Carlson, M. E., Gonzalez, O. \& Boechat, M. I. (1988). Effect of sex steroids on peak bone density of growing rabbits. American Journal of Physiology 255, E416-E421.

Roos, B. A., Cooper, C. W., Frelinger, A. L. \& Deftos, L. J. (1978). Acute and chronic fluctuations of immunoreactive and biologically active plasma calcitonin in the rat. Endocrinology 103, 2180-2186.

Russell, J. E., Morimoto, S., Birge, S. J., Fausto, A. \& Avioli, L. V. (1986). Effects of age and estrogen on calcium absorption in the rat. Journal of Bone and Mineral Research 1 185-189.

Schot, L. P. C. \& Schuurs, A. H. W. M. (1990). Sex steroids and osteoporosis: effects of deficiencies and substitutive treatments. Journal of Steroid Biochemistry and Molecular Biology 37, 167-182.

Takeuchi, A., Okano, T., Tsugawa, N., Katayama, M., Mimura, Y. \& Kobayashi, T. (1988). Determination of vitamin D and its metabolites in human and cow's milk. Journal of Micronutrient Analysis 4, $193-208$.

Tsuchita, H., Kuwata, T., Sakamaki, C., Kuwano, K., Shinoda, S. \& Yoshida, T. (1992). Bioavailability of calcium, phosphorus and magnesium from whey mineral complex in growing male rats. Zeitschrift für Ernärungswissenschaft 31, 258-268.

Tsuchita, H., Sekiguchi, I. \& Kuwata, T. (1993). Comparison of the effects of whey mineral complexes on bone metabolism in male growing rats. Journal of Nutritional Science and Vitaminology 39, 473-487.

Turner, R. T., Francis, R., Wakley, G. K. \& Evans, G. L. (1989). Progesterone regulates bone balance by antagonizing the inhibitory effects of estrogen on bone turnover. Journal of Bone and Mineral Research 4, Suppl. 1,377 .

Wolford, S. T. \& Argoudelis, C. J. (1979). Measurement of estrogens in cow's milk, human milk, and dairy products. Journal of Dairy Science 62, 1458-1463.

Wronski, T. J., Cintron, M. \& Dann, L. M. (1988a). Temporal relationship between bone loss and increased bone turnover in ovariectomized rats. Calcified Tissue International 43, 179-183.

Wronski, T. J., Cintron, M., Doherty, A. L. \& Dann, L. M. (1988b). Estrogen treatment prevents osteopenia and depresses bone turnover in ovariectomized rats. Endocrinology 123, 681-686.

Wronski, T. J., Walsh, C. C. \& Ignaszewski, L. A. (1986). Histologic evidence for osteopenia and increased bone turnover in ovariectomized rats. Bone $7,119-123$ 